\title{
Research on Legal Environment of Independent Innovation
}

\author{
Yanying Fei \\ Faculty of Humanities and Social Sciences \\ Dalian University of Technology \\ Dalian, China
}

\author{
Li Ling \\ School of Marxism \\ Dalian University of Technology \\ Dalian, China
}

\begin{abstract}
Independent innovation has become the core of development of national science and technology strategy after the 19th National Congress, and how to improve the ability of independent innovation of science and technology has become a major concern of the academic circle in China. The development of independent innovation needs sustained support, which is indispensable to strengthen the legal environment of independent innovation. Therefore, it is necessary to summarize the development status of China's legal environment for independent innovation. Furthermore, on this basis the paper studied the demand analysis of China's independent innovation legal environment from the aspects of intellectual property protection, financial and finance, transformation of scientific and technological achievements and the system of innovative talents mechanism.
\end{abstract}

Keywords-scientific and technological innovation; independent innovation;legal environment

\section{INTRODUCTION}

Since the beginning of the new century, independent innovation has been highly valued by the CPC central committee. China's national policy for medium and longterm scientific development (2006-2020) puts independent innovation in the height of the first of all scientific and technological work. The 17th CPC National Congress further emphasized to improve the ability of independent innovation and build an innovative country, which has accordingly formulated a national strategy on independent innovation. The 18th National Congress puts innovation at the core of national development and attaches great importance to scientific and technological innovation. It proposed the implementation of the innovation-driven development strategy to accelerate the comprehensive innovation centered on scientific and technological innovation. In 2015, the five development concepts proposed by Xi Jinping highlight the importance of innovative development concepts and emphasize the overall improvement of independent innovation capability, which also mean a greater emphasis on comprehensive promotion of independent innovation ability. The word "innovation" has been referred to more than 50 times in the reports of the 19th National Congress. And the reports proposed that we need to keep to the path of independent innovation with Chinese characteristics and improve our capacity for independent innovation in all areas of modernization. Thus, independent innovation has become a key issue in the field of political and economic. The development of independent innovation needs sustained support, which is indispensable to strengthen the legal environment of independent innovation. Our country come to realize the importance of legal regulation for the independent innovation, which result in the formulation of a series of laws and policies around scientific and technological innovation, forming a relatively complete legal system to regulate and guide the activity of independent innovation of science and technology. The legal regulation of independent innovation is also help for to realize the development of the economy. However, the support system for promoting and guaranteeing independent innovation in China is not perfect, and there are many gaps in the legislation of science and technology innovation, which lag behind the development of science and technology and economy. Therefore, the legal environment of China's independent innovation needs to be optimized and promoted urgently.

\section{THEORETICAL OVERVIEW OF INDEPENDENT INNOVATION}

On the concept of independent innovation, scholars have expounded at different research perspectives. At present, the main opinions are as follows: one viewpoint thinks that independent innovation means technological innovation. For example, $\mathrm{Fu}$ et al. argued that independent innovation was referred that the enterprise broken the technical difficulties mainly by their own efforts to form valuable research results. On this basis, the enterprises continued to promote the follow-up of innovation, completed the commercialization of technological achievements, and obtained commercial profits of the innovation activities [1]. Shang, vice minister of science and technology, proposed at the symposium on strengthening independent innovation in science and technology that independent innovation should include three aspects: the first one is to strengthen original innovation, the second is focus on integrated innovation in order to integrate the relevant technological achievements. Third, we should digest, absorb and recreate the technologies introduce. At this point, the connotation of independent innovation has specific definition. According to Liu al., independent innovation generally refers to the activity of innovation subject through its own power to achieve technological 
breakthrough, which can support and guide economic and social development and safeguard national security [2].

The second opinion is that independent innovation refers not only to scientific and technological innovation, but also non-technological innovation. Xie et al. believed that the independent innovation emphasized by China at the science and technology conference involved not only the technical field, but also the innovation of organizational management. Zheng et al. proposed that independent innovation mainly refers to scientific and technological innovation, and also includes institutional innovation, management innovation and cultural innovation. The third one is to define the connotation of independent innovation from the perspective of national strategy. In the other word, independent innovation means not relying on the technology of other countries, but relying on its own strength to conduct research and development and innovation activities independently. Shi et al. thought that independent innovation have different levels of meaning: At the national level, the independent innovation is used to show the characteristics of an organization or national innovation that is not dependent on technology import but rely on their own independent scientific and technological capabilities for technological innovation to achieve the goal of technology innovation. At the enterprise level, independent innovation is at the core of enterprise technological innovation [3]. The enterprise had broken the technical difficulties mainly by their own efforts to form valuable research results and products, which is the basis of the realization of commercial profit. This paper studied the connotation of independent innovation by the first academic view of point, that is, independent innovation is refers to the independent innovation of science and technology, which is relative to importation and imitation of the technology. The connotation of independent innovation is defined as the process of realizing the value of new products which is developed by unique core technology with independent intellectual property rights.

The legal environment is an organic whole mainly formed by legal ideology and its corresponding legal norms, legal systems, legal organizations, and legal facilities [4]. The legal environment and independent innovation interact and complement with each other, forming an organic whole that can promote economic growth. The main body of independent innovation is human beings. People have powerful subjective initiative. As a behavioral criterion, the system delineates human behavior and defines people's choice space. Therefore, how people solve problems is guided, encouraged or constrained by the legal system, ensuring that independent innovation activities are carried out orderly and healthily within the legal system. China's legal incentives and protection for technological innovation started relatively late but developed rapidly. Since the reform and opening up, China's laws related to technological innovation have been introduced, such as the "PRC Trademark Law", "PRC Patent Law", "PRC Science and Technology Progress Award Regulations", "PRC Copyright Law", "Computer Software Protection Regulations". The state continues to revise and improve the above laws in accordance with the practice of scientific and technological development, and basically forms a legal system that guarantees independent technological innovation, which greatly encourages the enthusiasm of independent innovation by enterprises and individuals.

Using legal means to regulate economic agents is the successful experience of market economy countries. Since the reform and opening up, a number of laws and regulations on technological innovation have been gradually formulated and implemented at home and abroad, but basic laws on national innovation systems have not yet been formulated. The existing scientific and technological progress laws can no longer meet the legal needs of independent innovation activities. At the same time, some relevant laws and regulations cannot fully reflect the principle of encouraging independent innovation, and there are still legal gaps in some important aspects. Therefore, China's legal system for innovation needs improvement. The legal system of intellectual property rights, the legal system of talents for scientific and technological innovation, the legal system for transforming scientific and technological achievements, and the financial and legal system should be further improved to promote the continuous improvement of the legal system for 1 innovation in China.

The legislation of science and technology lags behind, and there are some gaps in the legal system in areas such as science and technology system reform and scientific and technological innovation. In particular, economic legislation does not fully consider the needs of scientific and technological development. The basic laws and regulations of science and technology have a low order, and the science and technology laws that have been promulgated are mostly based on principles and guidelines, lack of binding and mandatory regulations, and are not operability. The science and technology innovation policy is scattered, the level is not high, the intensity is not strong, and the matching connection is not enough. In addition, the implementation of science and technology policy laws also lacks effective supervision and protection.

\section{ANALYSIS OF LEGAL ENVIRONMENT REQUIREMENTS FOR INDEPENDENT INNOVATION}

Whether a country has the ability to innovate independently and achieve innovation-driven economic development has become important indicators of whether the country has core competitiveness and whether it can achieve sustainable development. The level of independent innovation is related to the natural, political, economic and human environment and legal environment of a country. The legal environment is the most crucial factor. Therefore, improving the legal environment for safeguarding and promoting independent innovation should be the focus of scientific and technological innovation.

\section{A. Demands for the Legal System of Intellectual Property}

Nowadays, intellectual property rights are becoming decisive factors for enterprises to obtain actual rights of control and distribution, which directly reflect the profitability of products. In the process of national 
implementation of independent innovation strategy, protection of intellectual property rights is an issue that cannot be evaded. Intellectual property is an important scientific and technological resource.

Innovation of Enterprise must use and configure existing intellectual property resources reasonably and effectively in order to realize independent innovation of technology. In addition, as a legal system, intellectual property resources have played a correct guiding role for the company's innovation, promoted and ensured the company's innovation and protected the company's innovation results. After the industrial revolution in the UK, technological innovation became a powerful driving force for the development of economy. One of the most important reasons is that the United Kingdom has enacted a law for the purpose of protecting intellectual property rights. It has made innovations that cannot be protected by traditional legal systems effectively protect under this new legal system.

Although some scholars have pointed out that the level of intellectual property protection should be consistent with the protection of a country's level of economic and social development. The level of intellectual property protection that is too high or too low cannot promote independent innovation. At present, intellectual property protection in China does not have excessive problems but it is urgent to raise the level of protection. Due to the lack of effective laws and regulations, the protection of intellectual property rights has become the most easily overlooked part [5]. As a result, intellectual property rights infringement, counterfeiting and misappropriation are common occurrences which not only damage intellectual property owners and consumers but also are detrimental to the improvement of independent innovation capability of the entire country. Therefore, the key to the country's implementation of enhancing independent innovation capabilities and of innovation-driven development strategies is to strengthen intellectual property protection and create a stable legal environment and operating environment for enterprises.

\section{B. Demand for Financial Legal System}

The financial support is indispensable to shift China's economy from "imitation type" to "independent innovation type". Without financial support, no matter how good the technology can be, it can only be powerless. To promote independent innovation and establish a financial mechanism that supports innovation, the venture capital is the best hightech innovation financing mechanism. Therefore, to improve the financial legal system, the most important thing is to form an innovative venture capital investment mechanism. First, we should broaden the channels for innovative financing. In addition to obtaining bank credit support, we must also develop diversified financing channels to achieve independent innovation and development. We should change unreasonable policies and regulations and encourage private capital to support innovative enterprises. At present, the amount of private capital absorbed by domestic innovative companies is relatively low, and the burden of direct financing is relatively heavy. Therefore, there is an urgent need to enact and improve relevant laws and regulations in order to encourage private capital to invest in independent innovation industries and give full play to the power of private capital. In addition, encourage innovative companies to formulate new financing models, such as equity Financing, project financing, trust financing, and other forms of direct financing. In particular, the government needs to establish targeted financial support policies to speed up the promotion of financial leasing in light of the shortage of funds for innovative enterprises. In addition to the above, taxation is also the most common and direct means by which the government promotes technological innovation. The level of tax burden directly determines the amount of disposable income of the company after taxes, and also affects the amount of investment in corporate R\&D funds. Therefore, it is necessary to accelerate the implementation of the income tax system for domestic and foreign-funded enterprises so that both of them can bear the same tax burden which would encourage the innovative development of domestic-funded enterprises [6]. This series of legal measures of financial legal system guarantees that enterprises have the capability of independent innovation and development.

\section{Demand for Legal Systems of Transformation of Scientific Achievements}

The mechanism for the transformation of scientific and technological achievements is an important approach for the commercialization and industrialization of scientific and technological achievements. A perfect mechanism for transforming scientific and technological achievements can bring innovative benefits and greatly stimulate independent innovation activities of innovative entities. Developed countries attach great importance to the construction of legal systems for the transformation of scientific and technological achievements. Since the 1980s, the United States has enacted a series of laws including the "Small Enterprise Innovation and Development Law", the "Federal Government" s Technology Transfer Law", the "National Competitiveness Technology Transfer Law", the "National Technology Transfer and Upgrading Act" and the "Technology Transfer Business Act" to increase the conversion rate of scientific and technological achievements in the United States and promote the development of scientific and technological innovation. In 1999, the Japanese government promulgated the "Special Measures Act for Industrial Vitality Regeneration" which escalated the previously promulgated policies and measures to laws regulated and provided a legal and institutional basis for the transformation of scientific and technological achievements in many aspects. Since the new century, China also enacted a series of laws to guarantee and promote the transformation of scientific and technological achievements, such as the "People's Republic of China Law on Science and Technology Progress" and "The patent law", but the existing legal system for transformation of scientific and technological achievements in China does not have a long-term mechanism that is compatible with economic and technological development. Particularly, specific legal norms are also lacking [7].

The basic law on the development and management of science and technology has not yet been introduced, and the 
independent legal status of science and technology intermediary service agencies has not been established yet. The blankness of such related laws has caused the lack of legal authority and operability. In addition, China's current regulations of transforming scientific and technological achievements are mostly limited to the macroscopic level and lack specific institutional designs. The current related laws and regulations are not operability, and the supporting and concrete implementation measures are not perfect. For example, the provisions in the "Transformation of Achievements Law" about national financial input, tax incentives, risk funds, and evaluation of outcome values are overly principled, which have no procedural provisions and lack operability. The lack of provisions for valuation of scientific and technological achievements in the "Transformation of Achievements" law had led to the lack of legal basis for the distribution of benefits between related subjects. These various defects have dampened the enthusiasm of independent innovation of innovative entities to a certain extent, which also have restricted the development of independent innovation of science and technology. At present, it is necessary to strengthen the legislation for the transformation of scientific and technological achievements and to establish or improve a series of systems such as the taxation legal system and the evaluation of innovation achievements in China's further improvement of the mechanism for transforming scientific and technological achievements.

\section{Demand for legal system of Independent Innovation Talents}

Talent is a production factor with subjective initiative and high value-added, and the talent is the key to achieving independent innovation strategy. So we need to find ways to discover, attract, cultivate talents and stabilize talents. Therefore, it is necessary to formulate an effective talent introduction system and policies. First of all, China must actively create an atmosphere of "emphasizing talents and respecting talents". We must regard the introduction of external talents as an important part of the talent introduction policy, and we must adhere to the model of combining attraction and use. The government must vigorously promote talent introduction plans and policies and adopt a variety of channels and ways to introduce talents. Second, the government can also attract foreign talents through welfare policies such as wages, housing conditions, social insurance, children's relocation, and development opportunities. The arrival of external talents will promote the development of a talent team for the independent innovation and provide intellectual security for the sustainable development. Thirdly, training innovative talents also requires the formation of a scientific talent training model. The government must formulate corresponding policies and laws to protect personnel training. At the same time, it must pay attention to the cultivation of new people and the training of on-the-job personnel. In addition, we must clearly recognize that innovative talents can not only be cultivated theories by colleges, but must closely integrate the education of universities with the practice of enterprises. To this end, it is necessary to adopt the "school + enterprise" talent training model, which means that schools and enterprises will fully cooperate in order to make students integrate into the company's production practices, enhancing the ability of combination of theory and practice. Innovative enterprises must also strengthen the training of employees, including the establishment of a unique theoretical learning system which contributes to make up for their own deficiencies and apply the theoretical results of learning to practice to translate the theoretical knowledge learned into reality. Finally, the cultivation of innovative talents also requires a sound human resource management system, and the core of the system is the incentive and assessment of talents. Innovative companies need to rely on performance appraisal and salary distribution to establish a market-oriented talent incentive mechanism.

\section{CONCLUSION}

A number of laws and regulations on technological innovation have been gradually formulated and implemented in China, but basic laws on national innovation systems have not yet been formulated. Therefore, the legal environment of China's independent innovation needs to be optimized and promoted urgently. This paper studied the demand analysis of China's independent innovation legal environment from the aspects of intellectual property protection, financial and finance, transformation of scientific and technological achievements and the system of innovative talents mechanism.

\section{REFERENCES}

[1] J.J. Fu, "Technological Innovation,” Tsinghua University Press, pp. 96-98, 2000

[2] F.C. Liu, T.T. Feng, "The interaction between technical standard alliance partner relationship and alliance performance," Science Research Management, vol. 8, pp. 17-25, 2011.

[3] P.G. Shi, "The Imitative Innovation - A Strategic Option of Enterprises' Innovation in China,' Science \& Technology Review, vol 4, pp. 49-51, 1995.

[4] S.M. Zhang,X. Zhang, "An Empirical Study on the Policy and Legal Environment for the Growth of Small and Medium-sized Technology Enterprises," Journal of Shandong University(Philosophy and Social Sciences), vol. 01, 2014, pp. 103-110.

[5] Q. Zhang, "Research on Independent Innovation and Independent Intellectual Property," Intellectual Property, vol. 06, 2010, pp. 5-17.

[6] S.R. Lan,Q. Ma,L.J. Dong,'Discussion on Constructing the Legal Environment of Enterprise's Independent Innovation," Journal of Science, Technology and Law, vol. 03, 2006, pp. 11-18.

[7] J. L. Zhang, "Legal Perspective of Independent Innovation," Science \& Technology Progress and Policy, vol. 10, pp. 1-4, 2007 